\title{
The Newcastle exercise project: a randomised controlled trial of methods to promote physical activity in primary care
}

\author{
Jane Harland, Martin White, Chris Drinkwater, David Chinn, Lorna Farr, Denise Howel
}

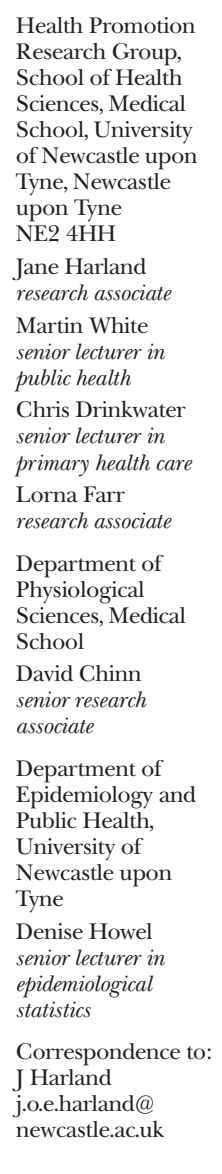

BMJ 1999;319:828-32

website

extra

Details of exclusion criteria may be

found on the

BMJ's website

www.bmj.com

\begin{abstract}
Objective To evaluate the effectiveness of combinations of three methods to promote physical activity.

Design Randomised controlled trial. Baseline assessment with post-intervention follow up at 12 weeks and 1 year.

Setting One urban general practice, 1995-7.

Participants 523 adults aged 40 to 64 years, randomised to four intervention groups and a control group.

Interventions Brief (one interview) or intensive (six interviews over 12 weeks) motivational interviewing based on the stages of change model of behaviour change, with or without financial incentive (30 vouchers entitling free access to leisure facilities). Main outcome measures Physical activity score; sessions of moderate and vigorous activity in the preceding four weeks.

Results Response rate was $81 \%$ at 12 weeks and $85 \%$ at one year. More participants in the intervention group reported increased physical activity scores at 12 weeks than controls (38\% v 16\%, difference 22\%, 95\% confidence interval for difference $13 \%$ to $32 \%$ ), with a $55 \%$ increase observed in those offered six interviews plus vouchers. Vigorous activity increased in 29\% of intervention participants and $11 \%$ of controls (difference $18 \%, 10 \%$ to $26 \%$ ), but differences between the intervention groups were not significant. Short term increases in activity were not sustained, regardless of intensity of intervention.

Conclusions The most effective intervention for promoting adoption of exercise was the most intensive. Even this did not promote long term adherence to exercise. Brief interventions promoting physical activity that are used by many schemes in the United Kingdom are of questionable effectiveness.
\end{abstract}

\section{Introduction}

Regular physical activity protects against cardiovascular diseases, obesity, diabetes, and osteoporosis ${ }^{1}$ and helps promote mental health. ${ }^{2}$ In the United Kingdom, $70 \%$ of men and $80 \%$ of women are insufficiently active to benefit their health. ${ }^{3}$ Over 200 "exercise on prescription" schemes have been identified in England ${ }^{4}$ but few have been rigorously evaluated. ${ }^{56}$ We present results from a randomised controlled trial evaluating the effectiveness of promoting physical activity in primary care.

\section{Methods \\ Participants}

Participants were recruited from one general practice (list size 11400 ) situated in a socioeconomically disad- vantaged area of Newcastle. ${ }^{78}$ All patients aged 40 to 64 years who satisfied our inclusion criteria were eligible to participate. Patients unable to complete a submaximal exercise test were excluded (patients with cardiovascular or respiratory disease causing raised risk), as were patients undertaking regular vigorous exercise at least three times a week over the previous six months. Exclusion criteria are described in more detail on the BMJ's website.

\section{Recruitment}

Between March 1995 and March 1996 the researcher (JH) approached all patients aged 40-64 attending routine surgeries. Patients completed a recruitment card, signed by their general practitioner, which they returned to the researcher before leaving. Postal recruitment was introduced between March and August 1996 to boost declining opportunistic recruitment. Patients not previously approached opportunistically were identified from the practice register, checked for eligibility, and sent a postal invitation to participate.

\section{Data collection}

Data were collected in three phases: baseline assessment; post-intervention follow up, 12 weeks after baseline (postal questionnaire); and repeat assessment one year after baseline, at which assessors were blind to allocated group (see figure 1). Baseline and follow up assessments lasted 75 minutes and included a structured interview questionnaire, physical measurements, and exercise test (cycle ergometer). Participants who refused the one year assessment were sent a follow up questionnaire. All non-respondents received one telephone reminder and two written reminders as required. Our null hypothesis was that changes in self reported physical activity at follow up would be the same in the intervention and control arms.

\section{Outcome measures}

Self reported physical activity was assessed by using a shortened version of the National Fitness Survey questionnaire that included questions on the type, frequency, duration and intensity of different activities in the previous four weeks. ${ }^{39}$ Activities were categorised as moderate, expending $5-7.5 \mathrm{kcal} / \mathrm{min}(0.209$ $0.314 \mathrm{MJ} / \mathrm{min}$ ), or vigorous, expending $>7.5 \mathrm{kcal} / \mathrm{min}$ $(>0.314 \mathrm{MJ} / \mathrm{min}) .^{3}{ }^{10} 11 \mathrm{~A}$ physical activity score was based on the number of sessions of moderate and vigorous activity lasting a minimum of 20 minutes in the previous four weeks. The score included all walking, cycling, and other sports or leisure activities but excluded home based activities (housework, gardening, and "do it yourself"). Scores were computed for respondents with complete physical activity data at each time period. Anthropometric, physiological, and 
other related outcomes, including changes in the variables of the exercise test, will be reported separately.

\section{Randomisation}

After their baseline assessment, participants were randomised in blocks of 10 . They chose blind from a set of 10 randomly ordered cards (two for each number from one to five, corresponding to the control group and four intervention groups) and were allocated to the corresponding group.

\section{Interventions}

All participants received their baseline results (blood pressure, weight for height, activity level and aerobic capacity, smoking, and alcohol consumption) and a pack containing information on the benefits of physical activity, other lifestyle factors (smoking, alcohol, weight, and diet), recommended activity levels for men and women of different ages, ${ }^{3}$ and 19 leaflets on leisure facilities and activities available locally. Brief advice was given, comparing individual's results with recommended levels and highlighting details in the information pack. Those in the control group received no further intervention.

Participants randomised to receive brief intervention (interventions 1 and 2) were offered one motivational interview within two weeks of their baseline assessment. Those receiving intervention 2 received 30 vouchers at the interview. Participants randomised to receive intensive intervention (interventions 3 and 4) were offered six motivational interviews over 12 weeks, the first within two weeks of the baseline assessment. Those in intervention 4 also received 30 vouchers at the first interview.

\section{Motivational interviewing}

Motivational interviewing is a technique for negotiating behaviour change ${ }^{12}$ that uses the stages of change model of behaviour change. ${ }^{13-16}$ A health visitor (LF), who was trained in motivational interviewing, delivered the motivational interviews. Interviews were scheduled to last 40 minutes and took place at the practice or local leisure centre. They aimed to promote safe, effective physical activity but did not prescribe particular activities. A structured record was completed at each interview, a copy of which was given to participants; this was used to review progress for those attending more than one interview.

\section{Financial incentive}

Vouchers were non-transferrable, valid during the intervention period, and could be exchanged for one episode of most aerobic activities in any local authority leisure centre, swimming pool, or other voluntary or community leisure activity in Newcastle. Date, place of use, and activity were recorded.

\section{Analysis}

A successful outcome was defined as moving up one or more levels of physical activity score from baseline to follow up. We calculated that 107 participants per group would be required to detect a difference between success rates of $40 \%$ to $60 \%$ at $80 \%$ power and $5 \%$ significance level.

Analysis, on the basis of intention to treat, was done with spss. ${ }^{17}$ The $\chi^{2}$ test for differences in proportions

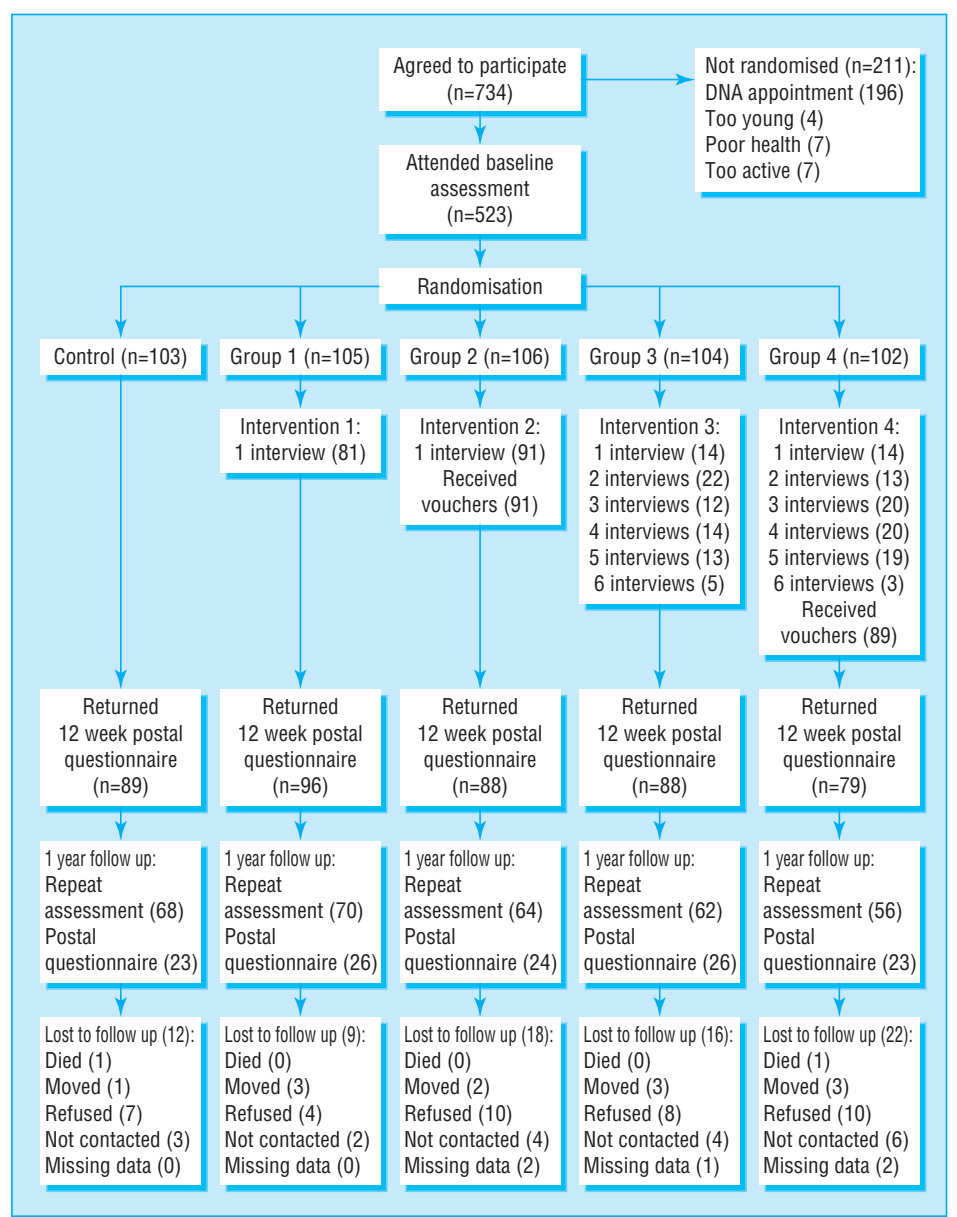

Flow of participants

was used to compare success rates across the five groups at follow up. If these showed significance $(\mathrm{P}<0.05)$, then the success rate in all intervention groups combined was compared with that in the control group. The rates within the intervention groups were compared by investigating the effect of extra interviews (interventions 1 and 2 combined versus interventions 3 and 4 combined), introduction of vouchers (interventions 1 and 3 combined versus interventions 2 and 4 combined), and interaction between extra interviews and vouchers, using logistic regression analysis. Confidence intervals for differences in proportions were calculated. ${ }^{18}$

Ethical approval was granted by Newcastle and North Tyneside Joint University and NHS Research Ethics Committee.

\section{Results}

\section{Recruitment and response rates}

In all, 2974 patients were approached (96\% of those aged 40-64 years): 1308 opportunistically and 1666 by post. Of these, $477(16 \%)$ were excluded and 734 agreed to participate. In total, 217 men and 306 women were enrolled. Baseline characteristics were evenly distributed in control and intervention groups (table 1).

The response rate at 12 weeks was $81 \%(n=424)$. Response at one year was $85 \%(n=442) ; 61 \%(321)$ attended the repeat assessment and 23\% (121) 
completed the postal questionnaire. Differences in response rates at 12 weeks and one year between intervention groups were not significant.

\section{Uptake of interventions}

Among participants in the intervention group, 341 $(82 \%)$ attended at least one interview. Attendance was higher in the interventions that included vouchers than the other interventions, $(86 \%$ (180) v $77 \%$ (161)). Among participants offered six interviews, the median number of interviews attended was three.

Of the 180 participants receiving vouchers, $41 \%$ (74) used at least one. Use of vouchers was higher in the intensive intervention than the brief intervention (44\% (45) v 27\% (29)). In total, 670 vouchers were exchanged; $69 \%$ (463) at the leisure centre nearest to the practice, $29 \%$ (196) at the local swimming pool, and $2 \%$ (11) at another swimming pool.

\section{Main outcomes}

At 12 weeks

The proportions with improved physical activity scores differed significantly in the four intervention groups combined, compared with the controls (38\% (123) $v$ $16 \%$ (13), $\mathrm{P}=0.001$ ) (table 2). Within the intervention groups, no significant effect was due to the introduction of vouchers $(\mathrm{P}=0.84)$ or more than one interview $(\mathrm{P}=0.26)$, but there was a significant interaction between these interventions $(\mathrm{P}=0.01)$ : the highest proportion of participants with increased physical activity scores $(55 \%)$ was in the group offered both multiple interviews and vouchers. This was 39\% (95\% confidence interval $25 \%$ to $53 \%$ ) more than in the control group.

The proportion of participants with an improvement in vigorous activity was significantly higher in the four intervention groups combined than the control

Table 1 Demographic and behavioural characteristics of participants at baseline. Values are numbers (percentages) of participants

\begin{tabular}{|c|c|c|c|c|c|c|}
\hline & $\begin{array}{l}\text { Control } \\
(n=105)\end{array}$ & $\begin{array}{c}\text { Intervention } 1 \\
(\mathrm{n}=105)\end{array}$ & $\begin{array}{c}\text { Intervention } 2 \\
(\mathrm{n}=106)\end{array}$ & $\begin{array}{c}\text { Intervention } 3 \\
(\mathrm{n}=104)\end{array}$ & $\begin{array}{c}\text { Intervention } 4 \\
(\mathrm{n}=103)\end{array}$ & $\begin{array}{c}\text { All interventions } \\
(\mathrm{n}=418)\end{array}$ \\
\hline Sex ratio (men:women) & $44: 56$ & $36: 64$ & $42: 58$ & $41: 59$ & $45: 55$ & $41: 59$ \\
\hline \multicolumn{7}{|l|}{ Age group: } \\
\hline $40-44$ & $27(26)$ & $28(27)$ & $20(19)$ & $32(31)$ & $20(19)$ & $100(24)$ \\
\hline $45-49$ & $22(21)$ & $17(16)$ & $32(30)$ & $23(22)$ & $27(26)$ & $99(24)$ \\
\hline $50-54$ & $21(20)$ & $24(23)$ & $17(16)$ & $15(14)$ & $21(20)$ & $77(18)$ \\
\hline $55-59$ & $13(12)$ & $16(15)$ & $22(21)$ & $13(13)$ & $15(15)$ & $66(16)$ \\
\hline $60-64$ & $22(21)$ & $20(19)$ & $15(14)$ & $21(20)$ & $20(19)$ & $76(18)$ \\
\hline \multicolumn{7}{|l|}{ Marital status: } \\
\hline Single (never married) & $8(8)$ & $10(10)$ & $8(8)$ & $6(6)$ & $4(4)$ & $28(7)$ \\
\hline Married or cohabiting & $79(75)$ & $79(75)$ & $85(81)$ & $75(72)$ & $78(76)$ & $317(76)$ \\
\hline Widowed, divorced, or separated & $18(17)$ & $16(15)$ & $12(11)$ & $23(22)$ & $21(20)$ & $72(17)$ \\
\hline \multicolumn{7}{|l|}{ Occupational class: } \\
\hline Non-manual (I, II, III non-manual) & $35(34)$ & $30(29)$ & $24(23)$ & $29(28)$ & $31(30)$ & $114(27)$ \\
\hline Manual (III manual, IV, V) & $69(66)$ & $75(71)$ & $79(77)$ & $74(72)$ & $71(70)$ & $299(72)$ \\
\hline \multicolumn{7}{|l|}{ Employment status: } \\
\hline Employed full or part time or self employed & $52(50)$ & $52(50)$ & $53(50)$ & $58(56)$ & $55(53)$ & $218(52)$ \\
\hline Unemployed and seeking work & $13(12)$ & $11(11)$ & $17(16)$ & $6(6)$ & $7(7)$ & $41(10)$ \\
\hline Unable to work due to illness & $15(14)$ & $17(16)$ & $13(12)$ & $14(14)$ & $12(12)$ & $56(13)$ \\
\hline Retired & $12(11)$ & $18(17)$ & $10(9)$ & $13(13)$ & $19(18)$ & $60(14)$ \\
\hline Looking after home and family, or other & $13(12)$ & $7(7)$ & $12(11)$ & $13(13)$ & $10(10)$ & $42(10)$ \\
\hline \multicolumn{7}{|l|}{ Housing tenure: } \\
\hline Owner occupier & $57(54)$ & $68(65)$ & $60(57)$ & $57(55)$ & $62(60)$ & $247(59)$ \\
\hline Rented from city council & $40(38)$ & $32(31)$ & $40(38)$ & $40(39)$ & $33(32)$ & $145(35)$ \\
\hline Rented privately & $7(7)$ & $1(1)$ & $2(2)$ & $2(2)$ & $5(5)$ & $10(2)$ \\
\hline Other & $1(1)$ & $4(4)$ & $4(4)$ & $5(5)$ & $3(3)$ & $16(4)$ \\
\hline \multicolumn{7}{|l|}{ Car and phone ownership: } \\
\hline Car owner & $59(56)$ & $66(63)$ & $65(61)$ & $66(64)$ & $67(65)$ & $264(63)$ \\
\hline Phone owner & $94(90)$ & $102(97)$ & $100(94)$ & $97(93)$ & $92(89)$ & $391(94)$ \\
\hline \multicolumn{7}{|l|}{ Age left full time education: } \\
\hline$\leqslant 14$ & $12(11)$ & $8(8)$ & $8(8)$ & $13(13)$ & $12(12)$ & $41(10)$ \\
\hline 15 & $64(61)$ & $64(61)$ & $64(60)$ & $60(58)$ & $65(63)$ & $253(61)$ \\
\hline $16-18$ & $29(28)$ & $31(30)$ & $28(26)$ & $29(28)$ & $19(18)$ & $107(26)$ \\
\hline$\geqslant 19$ & $0(0)$ & $2(2)$ & $5(5)$ & $2(2)$ & $7(7)$ & $16(4)$ \\
\hline \multicolumn{7}{|l|}{ Physical activity score: } \\
\hline Level 0 (no sessions moderate or vigorous) & $68(65)$ & $65(62)$ & $60(58)$ & $58(56)$ & $72(70)$ & $255(61)$ \\
\hline Level 1 (1-4 sessions moderate or vigorous) & $20(19)$ & $20(19)$ & $19(18)$ & $21(20)$ & $15(15)$ & $75(18)$ \\
\hline Level 2 (5-11 sessions moderate or vigorous) & $8(8)$ & $8(8)$ & $14(14)$ & $10(10)$ & $10(10)$ & $42(10)$ \\
\hline Level 3 ( $\geqslant 12$ sessions moderate) & $5(5)$ & $7(7)$ & $4(4)$ & $9(9)$ & $1(1)$ & $21(5)$ \\
\hline Level 4 ( $\geqslant 12$ sessions moderate or vigorous) & $1(1)$ & $4(4)$ & $3(3)$ & $3(3)$ & $4(4)$ & $14(3)$ \\
\hline Level 5 ( $\geqslant 12$ sessions vigorous) & $3(3)$ & $1(1)$ & $4(4)$ & $3(3)$ & $1(1)$ & $9(2)$ \\
\hline \multicolumn{7}{|l|}{ Achieving target level of activity: } \\
\hline Yes & $6(6)$ & $7(7)$ & $11(11)$ & $13(13)$ & $6(6)$ & $37(9)$ \\
\hline No & 99 (94) & $98(93)$ & $93(89)$ & $91(88)$ & $97(94)$ & $379(91)$ \\
\hline
\end{tabular}

Intervention 1: one motivational interview within two weeks of baseline assessment; intervention 2: one motivational interview within two weeks of baseline assessment plus 30 vouchers; intervention 3: six motivational interviews over 12 weeks; intervention 4: six motivational interviews over 12 weeks plus 30 vouchers. 
Table 2 Number (percentage*) of participants with improvements in self reported measures of physical activity at 12 weeks and 1 year

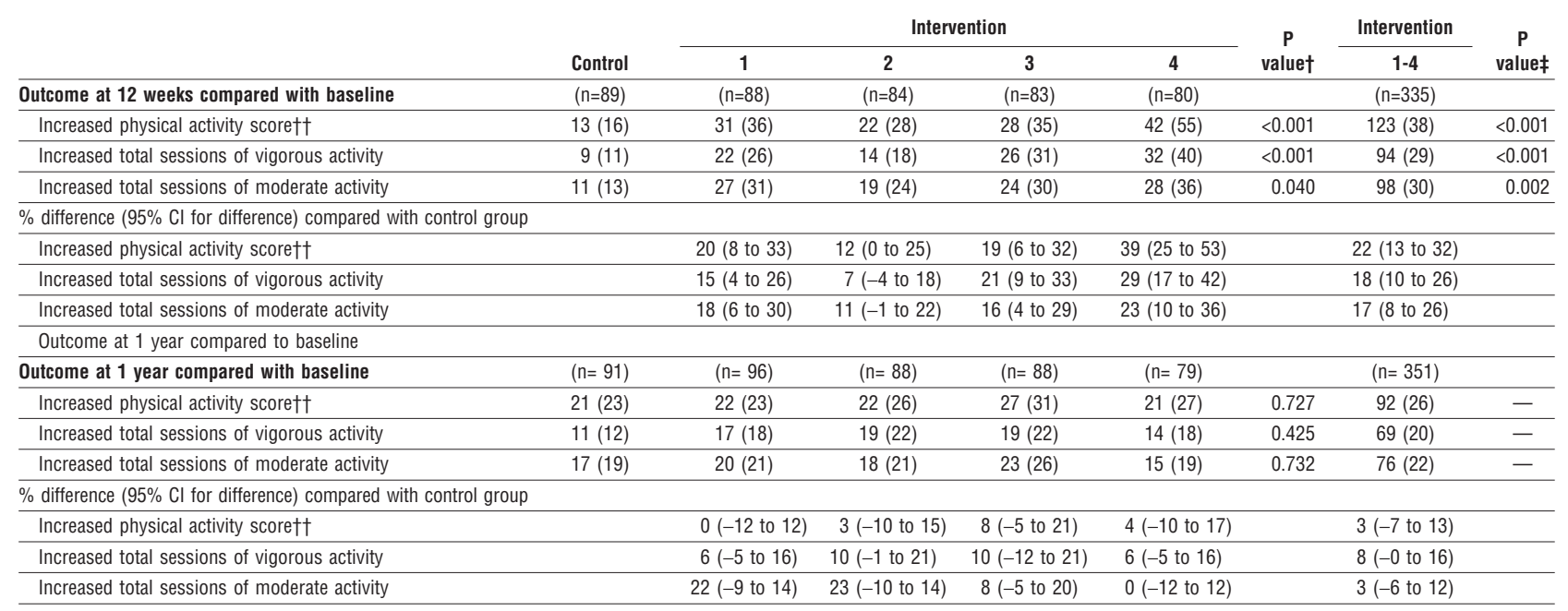

Intervention 1: one motivational interview within two weeks of baseline assessment; intervention 2: one motivational interview within two weeks of baseline assessment plus 30 vouchers:

intervention 3: six motivational interviews over 12 weeks; intervention 4: six motivational interviews over 12 weeks plus 30 vouchers.

${ }^{*}$ Calculated using total respondents with complete data for each variable as the denominator.

$\dagger \chi^{2}$ test for proportions comparing five groups. $\neq \chi^{2}$ test for proportions comparing intervention and control arms.

††Physical activity score increased by one or more levels from baseline to follow up.

group (29\% (94) v 11\% (9), $\mathrm{P}<0.001$; difference $18 \%$, $10 \%$ to $26 \%$ ). However, within the four intervention groups there were no significant effects due to interviews $(P=0.4)$, vouchers $(P=0.21)$, or the interaction between them $(\mathrm{P}=0.09)$. The improvement in moderate activity was significantly greater in the four intervention groups than the control group (30\% (98) v $13 \%$ (11), $\mathrm{P}=0.002$; difference $17 \%, 8 \%$ to $26 \%$ ). However, there was no significant effect due to interviews $(\mathrm{P}=0.80)$, vouchers $(\mathrm{P}=0.27)$, or the interaction effect between them $(\mathrm{P}=0.16)$.

\section{At one year}

Increases in physical activity reported at 12 weeks by participants in the intervention group were not maintained at one year, regardless of the intensity of intervention. Only the increase in vigorous activity in the intervention groups was close to statistical significance. The data were consistent with small positive or negative effects of intervention groups compared with controls.

\section{Discussion}

\section{Interpretation}

Adoption of physical activity (initiation of increased physical activity in previously sedentary individuals) and adherence to physical activity (long term maintenance of increased physical activity) have been described as distinct phases of activity behaviour influenced by different factors. ${ }^{19}{ }^{20}$ This trial evaluated interventions to promote adoption of physical activity in socioeconomically disadvantaged, middle aged adults. The most effective intervention was the most intensive, apparently due to synergy between motivational interviewing and financial incentive. A comparatively brief intervention (one motivational interview) was effective for only a third of participants in the short term. Results at one year showed that short term increases in physical activity were not maintained. Even the most intensive intervention was ineffective in promoting adherence to exercise in the absence of further incentives to maintain changes in lifestyle.

\section{Limitations}

The study was experimental, ${ }^{21}{ }^{22}$ with most of the recruitment, intervention, and evaluation functions undertaken by research staff. Our recruitment rate (17\%) was considerably higher than other exercise on prescription schemes, which have typically involved less than $1 \%$ of the patient base from which they were drawn; this may have been facilitated by the researcher being in the practice to initiate recruitment daily.

Opportunistic recruitment was effective initially but led to diminishing returns as the number of eligible patients fell from 20 to three per surgery over a year. About a third of these patients were excluded, the majority on health grounds. Postal recruitment enabled further participants to be enrolled, but they were more likely to be in employment and in better health. ${ }^{23}$ Although opportunistic recruitment consumed more resources in terms of time and missed appointments, it seems to have targeted those with more to gain from participation in physical activity than did postal recruitment. Recruitment rates have been shown to affect the cost effectiveness of physical activity interventions. ${ }^{24}$ Further research is required to develop recruitment strategies tailored to different population subgroups.

Participants were recruited from an area with high levels of socioeconomic disadvantage. As physical activity, and perceived barriers to physical activity, vary with socioeconomic status, ${ }^{25}$ the effectiveness of the interventions may vary in different population subgroups. Patients enrolled in the trial represent those most willing to comply. Response rates at follow up are likely to be higher than expected in a normal primary care setting, but provide insight into the likely uptake of physical activity promotion offered as routine preventive care. 
Key messages

- Schemes promoting physical activity are currently popular in general practice in Britain, but few have been rigorously evaluated and their effectiveness is unknown.

- In this study, the most effective intervention for promoting adoption of physical activity was the most intensive, involving six motivational interviews and a financial incentive

- A comparatively brief intervention (one interview) was only effective in the short term in around a third of participants

- Short term increases in physical activity were not maintained at one year follow up and even the most intensive intervention was ineffective in promoting long term adherence to increased physical activity.

- National and local government, health authorities, and primary healthcare teams should be cautious about current and future expenditure on, and implementation of, exercise prescription or referral schemes

The baseline assessment received by participants in the control group represents a considerable intervention and may have diluted the apparent results of the intervention. The proportion in the control group reporting increased physical activity at one year $(23 \%)$ is higher than that in a similar trial where the control group received information only $(23 \% v$ $13 \%) .^{24}$

Restricted access to surgery premises (surgery hours only) may have excluded patients in full time employment . Alternative strategies may be necessary to target the working population. Outcome measures were based on self reported data and may be subject to reporting bias.

\section{Implications}

The results of this trial have important implications for the organisation and effectiveness of physical activity promotion in primary health care. ${ }^{4-6}$ In light of our findings, primary healthcare teams need to assess critically the interventions that are currently used to promote physical activity, and they should reconsider the use of scarce resources to fund "exercise prescription" schemes. Further research is needed to develop interventions that promote long term adherence to exercise in addition to adoption of exercise and to identify less costly ways of delivering these.

There is a need to base policy on evidence, and not simply on fashion and the apparent popularity of current schemes. This is particularly important given the increasing emphasis placed on physical activity by current government initiatives in Britain such as Healthy Living Centres. ${ }^{26}{ }^{27}$

We thank all the staff at Walker Medical Group; Linda Norris, at Community and Leisure Services, Newcastle City Council; Drs Jim Reed and Andy Binks, for help and advice with exercise testing; Wyn Raine, Janet Jewitt, and Marion Hancock for secretarial support; Peter James for providing training in motivational interviewing and support to Lorna Farr; Josie Wilson for help with data processing and collection; all the staff at the Lightfoot Leisure Centre. Lastly we would like to express our special thanks to all of the participating patients from Walker Medical Group for their time and support.

Contributors: MW and CD conceived the study and obtained funding in collaboration with $\mathrm{DH}$. $\mathrm{JH}$ further developed the study design and, with DC and LF, collected and processed the data. LF was responsible for implementing the interventions. Data analysis was carried out by $\mathrm{JH}$ and $\mathrm{DH}$, with advice from MW and DC. JH and MW were responsible for drafting this paper, with contributions from DH. All authors contributed to data interpretation and commented on drafts of the paper. JH, MW, and CD are guarantors.

Funding: The Newcastle exercise project was funded by the NHS National R\&D Programme on Cardiovascular Disease and Stroke (grant number HB32).

Competing interests: None declared.

1 Fentem PH. Benefits of exercise in health and disease. BMJ 1994;308:1291-5.

2 Byrne A, Byrne DG. The effect of exercise on depression, anxiety and other mood states: a review. J Psychosom Res 1993;37:565-74.

3 Sports Council, Health Education Council. Allied Dunbar national fitness survey: main findings. Northampton: Sports Council, Health Education Authority, 1992.

4 Fox K, Biddle S, Edmunds L, Bowler I, Killoran A. Physical activity promotion through primary health care in England. Br J Gen Pract 1997:47:367-9.

5 Taylor A. Evaluating GP exercise referral schemes: findings from a randomised controlled study. Brighton: Chelsea School Research Centre, University of Brighton, 1996. (CSRC topic report 6.)

6 Riddoch C, Puig-Ribera A, Cooper A. Effectiveness of physical activity promotion schemes in primary care: a review. London: Health Education Authority, 1998

7 Harvey J. Health profiles by locality. Newcastle upon Tyne: Directorate of Public Health, Newcastle and North Tyneside Health Authorities, 1995.

8 Harrington B, White M, Raybould S, Foy C, Blades S, Harvey J. Indicators for health promotion: ward based analyses from the NHLS 91. Newcastle upon Tyne: Newcastle Health Authority and Department of Epidemiology and Public Health, University of Newcastle, 1994.

9 Breeze E, Maidment A, Bennett N, Flatley J, Carey S. Health survey for England 1992: a survey carried out by the social survey division of OPCS on behalf of the Department of Health. London: HMSO, 1994.

10 Fentem P, Collins M, Tuxworth W, Walker A, Hoinville E, Cooke C, et al. Allied Dunbar national fitness survey:technical report. London: Sports Council and Health Education Authority, 1994.

11 McArdle W, Katch F, Katch V. Exercise physiology: energy, nutrition and human performance. 3rd ed. Philadelphia: Lea and Febiger, 1991.

12 Miller W, Rollnick S, eds. Motivational interviewing: preparing people to change addictive behaviour. London: Gilford Press, 1991.

13 Prochaska J, DiClemente C. Stages and processes of self-change in smoking: towards an integrative model of change. J Consult Clin Psychol $1983 ; 51: 390-402$.

14 Prochaska J, Marcus B. The transtheoretical model: applications to exercise. In: Dishman R, ed. Advances in exercise adherence. Champaign, IL: Human Kinetics, 1994:161-80.

15 Marcus BH, Simkin LR. The stages of exercise behaviour. J Sports Med Physical Fitness 1993;33:83-8.

16 Buxton K, Wyse J, Mercer T. How applicable is the stages of change model to exercise behaviour? A review. Health Educ J 1996;55:239-57.

17 SPSS. The Statistical Package for Social Sciences (SPSS/PC+). 6.0 ed. Chicago: SPSS, 1996.

18 Gardener M, Altman D. Confidence interval analysis. London: BMJ, 1991.

19 King A. Clinical and community interventions to promote and support physical activity participation. In: Dishman R, ed. Advances in exercise adherence. Champaign, IL: Human Kinetics, 1994:183-212.

20 Sallis JF, Hovell MF. Determinants of exercise behaviour. Exercise Sports Sci Rev1990;18:307-30.

21 Nutbeam D. Achieving 'best practice' in health promotion: improving the fit between research and practice. Health Educ Res 1996;11:317-26.

22 Nutbeam D. Evaluating health promotion-progress, problems and solutions. Health Promotion Int 1998;13:27-44.

23 Harland J, White M, Drinkwater C, Chinn D, Farr L. Does recruitment strategy affect participation and interim outcome in a randomised controlled trial evaluating physical activity promotion in primary health care? J Epidemiol Community Health 1997;51:587-8.

24 Stevens W, Hillsdon M, Thorogood M, McArdle D. Cost-effectiveness of a primary care based physical activity intervention in 45-74 year old men and women: a randomised controlled trial. Br J Sports Med 1998;32: 236-41.

25 Chinn D, White M, Harland J, Drinkwater C, Raybould S. Barriers to physical activity and socio-economic position: implications for health promotion. J Epidemiol Community Health 1999;53:191-2.

26 Secretary of State for Health. Our healthier nation: a contract for health. London: Stationery Office, 1998.

27 Health Education Board for Scotland. The promotion of physical activity in Scotland. Edinburgh: Health Education Board for Scotland., 1995.

(Accepted 29 July 1999) 